\title{
Busway distribution system-sizing \& planning aspects for automotive weld shop
}

\author{
Sana Zaheer, Raja Masood Larik
}

Department of Electrical Engineering, NED University of Engineering and Technology, Karachi, 75270, Pakistan

\begin{tabular}{l} 
Article Info \\
\hline Article history: \\
Received Jan 18, 2021 \\
Revised May 19, 2021 \\
Accepted Jun 28, 2021 \\
\hline
\end{tabular}

\section{Keywords:}

Bus way distribution Intermittent load Stochastic problem Thermal equivalence Voltage drop Weld quality

\begin{abstract}
Resistance spot welding with its characteristic "dirty electrical load" is a distinctive engineering problem. The wide range of its industrial applications has made the subject an exciting research domain. Owing to the intermittence of a welding operation, random overlapping of welding pulses, its sensitivity to voltage variation, and application-specific quality control requirements, the electrical distribution system for welding loads need to be tied strongly with the process-related requirements. One of the most important applications of resistance welding is an automotive body shop, also called weld shop. This is where various units of a car body are welded together to form a shell that begins to look like a car. This paper focuses on explaining the nature of welding load and process requirements of a weld shop, leading towards the design and development of a Microsoft Excel based tool for optimal sizing of high current busway distribution system for resistance spot welding machines. This tool can be effectively used as a desktop application for efficient design development and comprehension of various design criteria. Besides, numerical based calculations have been provided with sound reasoning, progressively developing the proposed design criteria.
\end{abstract}

This is an open access article under the CC BY-SA license.

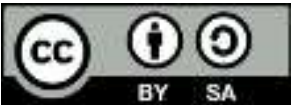

\section{Corresponding Author:}

Raja Masood Larik

Department of Electrical Engineering

NED University of Engineering and Technology

Main University Rd, Karachi City, Sindh 75270

Email:rmlarik@neduet.edu.pk

\section{NOMENCLATURE}

$\mathrm{I}_{\mathrm{w}} \quad$ Welding current

$I_{\text {th }} \quad$ Thermal equivalent current

$\mathrm{I}_{\text {th-L }} \quad$ Thermal equivalent line current

$\mathrm{I}_{\mu} \quad$ Expected value of thermal equivalent current

$\mathrm{I}_{\mathrm{c}} \quad$ Contingent value of thermal equivalent current

$\mathrm{R}_{\mathrm{l}} \quad$ Resistance of a conductor/feeder per unit length (expressed in $\Omega / \mathrm{m}$ )

$\mathrm{X}_{\mathrm{l}} \quad$ Inductive reactance of a conductor/feeder per unit length (expressed in $\Omega / \mathrm{m}$ )

L Length of bus bar feeder

$\mathrm{K}$ Load distribution factor of a bus bar feeder

$\mathrm{T}_{\mathrm{w}} \quad$ Duration of welding
T Integration period of welding operation

D Duty cycle of welding operation

L1/L2/L3 A single line in a three phase AC system

L1-L2, A line to line group in a there phase AC

L2-L3, system

L3-L1

$\mathrm{n}$

$\mathrm{k} \quad$ Number of welders welding simultaneously

$\mathrm{P}_{\mathrm{k}} \quad$ Probability of $\mathrm{k}$ welders out of " $\mathrm{n}$ " total welders, welding at a time

$\mathrm{P}_{\mathrm{b}} \quad$ Allowable proportion of bad welds

W' Number of welders for which voltage dips below the allowable limit 


\section{INTRODUCTION}

Resistance spot welding is one of the most extensively employed methods of joining pressed metal sheets in the automotive industry [1]. The welding operation takes place in a weld shop or body shop. This is the very workshop in an automobile manufacturing plant, where a vehicle gets its shape [2]. There are around 3000 to 5000 spot welding joints in a typical vehicle [3], [4]. Whenever a new car model is to be launched, there required is a new body shop or complete revamping of the existing shop to cater to the new unique needs [5].

The fact that the resistance spot welding does not require any additional filler material for making the joint, makes it inexpensive and efficient [6], [7]. The process, however, is a multifaceted engineering problem and the comprehension of various process-related requirements is a prerequisite for effective planning of electrical supply and distribution architecture [8]. The welding operation is intermittent. It derives high current for durations as small as 1 to10\% of the welding cycle [9], [10]. In the absence of interlocking of the welding machines, a lot of welding may take place simultaneously [11]. Not only the supply must be able to cater to the load requirement, but the distribution system must also be able to sustain that current. Yet the distribution system cannot be sized for that much high current.

However, considering manual actuations with random initiations, a very large percentage of simultaneous operations is hard to imagine, especially with many machines connected to a line. This instates the need for stochastic analysis of the welding operation, hinting towards the most probable scenario [12]. In addition to load intermittence and randomness of operation, the welding process is also vulnerable to voltage instability and supply quality deterioration. When sufficient power is not available for welding, bad or cold welds result, leading to reduced productivity and compromised profits. In order to quantify an acceptable amount of trouble, a limit is set to the number of spoilt welds called the allowable proportion of bad welds [12]-[14]. The prevalent use of high current busways in the automotive industry provides the flexibility of operation and ease of expandability [15], [16]. The resulting decentralized distribution system enables the utilization of the randomness of welding operation in design interest.

This research provides a systematic review on the nature of welding load and unique rudiments of automotive weld shop, streamlining the multifaceted design criteria for optimal sizing of distribution busway for automotive weld shop. The methodological numerical analysis presents a stepwise solution catering to each design criterion. Additionally, a Microsoft excel based design tool is developed easing the calculations elucidated. This paper targets to provide a one window solution to a novice designer of the busway distribution system for an automotive weld shop.

\section{DISCUSSION}

\subsection{Nature of welding load}

Use of single phase spot welding machines is prevalent in automotive industry. On a 400V network, these spot welding machines are supplied through two phases. Therefore these machines are often referred to as two phase machines [17]. These machines work on Joule effect. The energy required for welding is supplied by the energy expressed as heat upon circulation of high magnitude current though the metal parts to be joined. The work-pieces are held together under pressure, exerted by electrodes. The amount of heat available for welding depends on the resistance between the electrodes, and amplitude and duration of the current. The resistance at the junction of the metal pieces opposes the flow of current. The energy required to overcome the junction resistance is expressed as heat and raises the metal temperature. The metal melts and forms a welding nugget at the interface [18], [19].

\subsection{Welding operation}

The welding operation is a series of discrete time events. One complete welding cycle follows following sequence:

\section{Squeeze Time $\rightarrow$ Weld Time $\rightarrow$ Hold Time $\rightarrow$ Off time}

The welding process begins with the metal pieces being held together under the electrode force until the desired force is attained. This duration is called squeeze time. During this while, no welding current is applied. Once sufficient force is attained, the welding current is allowed to flow. The duration for which the welding current flows through the metal pieces, is called weld time. It is expressed in cycles of supply voltage. A welding duration, too long, causes expulsion of molten metal from the electrode surfaces. Conversely, a duration too short yields a cold weld. Weld time is followed by hold time, when the electrode force is continued to be applied on the work pieces, to allow the weld nugget to solidify before the electrodes are retracted. When the welding cycle is repetitive, an off time defines the duration between retraction of electrodes from one workpiece and their application on other. It is only the weld time, when the welding current is required. For rest of the duration, the supply needs to not to be committed [18], [20]. 


\subsection{Concept of intermittence}

To further clarify the nature of welding load, it is important to introduce here a term "duty cycle". Duty cycle is the ratio of the time for which a load is applied and the "Integration period" for the device, expressed in percentage. An integration period is the duration summing a load and a rest period. A comparison of currents at different duty cycles is given in Figure 1. Load at $5 \%$ duty cycle derives current for only $5 \%$ of the total integration period $(20 \mathrm{~ms})$ however the load at $50 \%$ duty cycle conducts current for $10 \mathrm{~ms}$ i.e. half the integration period. Duty cycle for welding operation ranges from 1 to $10 \%$. In other words, the weld time accounts for only 1 to $10 \%$ of the welding operation.

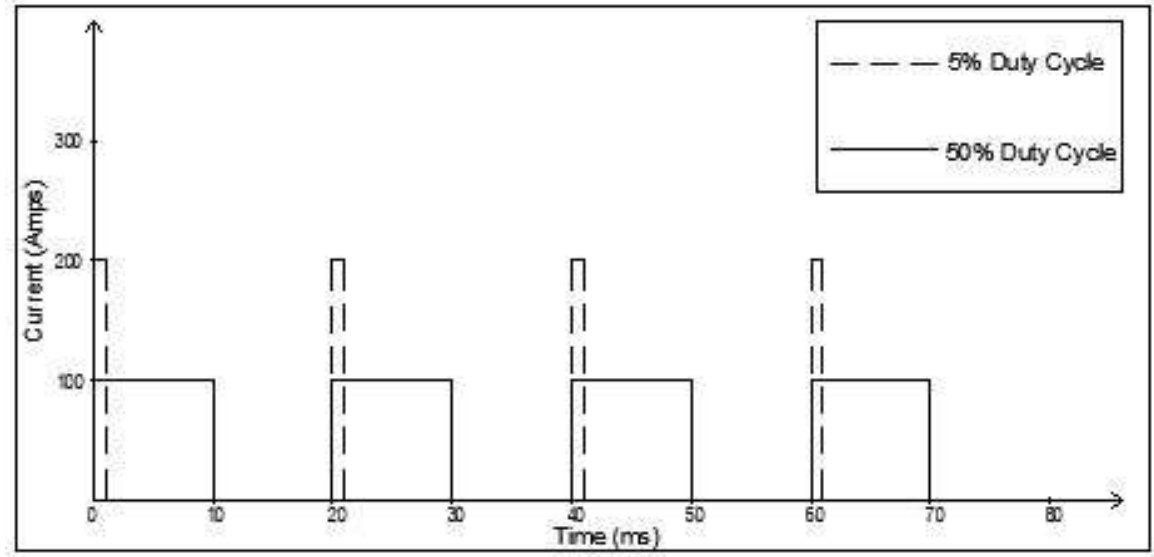

Figure 1. Depiction of $5 \%$ and $50 \%$ duty cycle

\subsection{Thermal equivalence-the key to overloading without overheating}

The electrical power supply and distribution systems are designed to carry the rated power continuously throughout their rated life. The fact that the welding load derives the welding current for a small period of time, instigates that a supply or distribution equipment can support more than its rated load without getting overheated.

Electrical energy convertible to thermal energy is given by:

$$
E=I^{2} R t
$$

With constant opposition, higher the magnitude of current or longer the duration of conduction, higher will be the electrical energy lost as heat. It is this heating of the equipment that limits its operation at loads higher than its rating. Equalizing the heat produced by a current " $I$ " passing for " $t$ " seconds with another current " $I$ "” passing for " $t$ ", seconds.

$$
I^{\prime}=I \sqrt{ } \frac{t}{t^{\prime}}=I \sqrt{ } \frac{D}{D^{\prime}}
$$

Equation 2 tells that a current of a high magnitude of $1000 \mathrm{~A}$ flowing intermittently with a duty cycle of 5\% is thermally equivalent to $\approx 224 \mathrm{~A}$ flowing continuously. The distribution system equipment, need not to be sized at 1000A. A continuous current rating of around 224A should suffice. Equation 2 expressed in terms of welding parameters gives the thermal equivalent current corresponding to any welding current [8], [9], [13], [21]:

$$
I_{t h}=I_{w} \sqrt{\frac{T_{W}}{T}}=I_{w} \sqrt{D}
$$

\subsection{Voltage Drop}

Concerning the design of welding networks, another consideration is to handle the voltage dips due to random overlapping of welding pulses. In most applications, the voltage drop is limited to $10 \%$ of the supply voltage. $10 \%$ drop doesn't seem much of a hassle, however, as the power line voltage drops by $10 \%$, the available electrical energy convertible to thermal energy, required for welding, decreases by $19 \%$. Unavailability of sufficient energy for welding results in poor quality welds. 
For a group of welders connected to the same bus bar, the cause of bad weld at a welding gun is not only the voltage drop due to the welder itself but also due to the other welders welding at the same time [11]. The voltage drop limit is application-specific. 10\% limit for voltage drop is a generalized criterion for welding of mild steel. For other materials like aluminum for which the effect of variations in heat may be more severe, the allowable voltage drop may be less than $10 \%$ [9].

\subsection{Quality of weld}

The quality of a weld can be expressed in three ways:

- Physical or geometrical features like cracks and porosity.

- Strength or performance.

- Process characteristics e.g. visible expulsion of molten metal from electrode surface [8].

Due to a variety of reasons, some welds do not pass the quality test and are called "bad or cold weld".

Following are some reasons for bad welds:

- Defects in material.

- Wear and tear of electrode tips.

- Insufficient supply voltage.

The importance of a stable and sufficient supply voltage has already been established in previous section, however, not all drops in voltage are due to the welding current. Following are some non-welding reasons of voltage drop:

- Other loads connected to same source.

- Excessive length of feeder from the transformer.

- Fault in any feeder or elsewhere in the network.

- Poor voltage quality from utility.

- Other industrial consumers on same network.

For the purpose of regulating the quality of welds, both welding and non-welding reasons for bad welds need to be controlled [9].

\subsection{Allowable proportion bad welds}

As established, the number of spoilt welds is not equal to the number of welds for which the voltage drops below the assigned limit. Therefore, the allowable proportion of welds for which the voltage drop is allowed to drop below the assigned limit must be less than the actual permissible limit of bad welds. The limit is decided in consultation with the plant engineers and expressed in percentages. It is user's prerogative to decide, based on the length and cost of the rectification process, the number of bad welds permissible. A limit of $1 \%$ means that it is acceptable if one out of a hundred welds is of poor quality [9]. As follows logically, there required is a way to calculate the odds of supply voltage dropping below the allowable limit. If the possibility of such occurrence turns out to be less than the allowed limit of bad welds, then the design turns out to be acceptable.

\subsection{Welding operation as a bernoulli trial}

The welding process by nature of operation is a stochastic problem. The probability of any number of welders welding at an instant can be expressed as a binomial distribution [10]. A Binomial distribution depicts that the outcome of a trial can only assume one of two independent values under assumptions, listed below:

- There's only one outcome for each trial.

- Each trial has same probability of success.

- Each trial is independent of previous trials.

Binomial distribution can also be regarded as the sum of a series of multiple independent and identically distributed Bernoulli trials. A Bernoulli trial is an experiment which is random and could generate only one of the two possible outcomes: success or failure. In other words, the Bernoulli distribution is a special case of the binomial distribution where the number of trials $n=1[22]$.

For welding operation there are only two possible states; welding and rest, both the states are independent of each other and mutually exclusive i.e. either a welder welds or welds not, there's no third possibility and no chance of overlap of the two states. Consequently, the evaluation of welding operation at any instant is a Bernoulli trial. The probability of success i.e. welding for every instant is same and equal to duty cycle of the operation. The outcome of one trial doesn't in any way have an effect on other trials. Then, $P_{k}$ i.e. probability of $k$ welders out of " $n$ " total welders, welding at a time is given by following relation [10]:

$$
P k=\left(\begin{array}{l}
n \\
k
\end{array}\right) D^{k}(1-D)^{n-k}
$$




\section{NUMERICAL ANALYSIS}

Based on Bernoulli equation, consider an example of 20 welding machines connected to a group (L1-L2/L2-L3/L3-L1), welding intermittently for two different processes with different duty cycles; $6 \%$ and $10 \%$. Following results can be obtained in Figure 2.

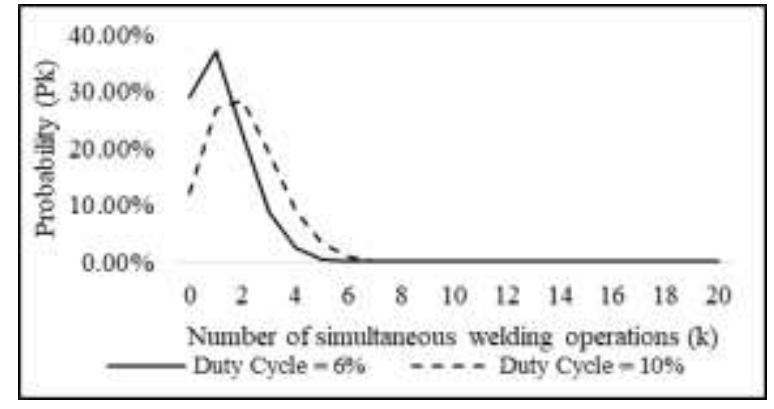

Figure 2. Probability of simultaneous welding operations as given by Bernoulli's equation

It can be observed from Figure 2 that simultaneity curve follows binomial distribution. When the duty cycle of an operation increases, there is more possibility of simultaneous operations. For any practical value of duty cycle, there is absolutely minimal chance of all the welders welding together. For $6 \%$ duty cycle there's a fair chance $(66 \%)$ that none or only 1 welder would weld at a time. For $10 \%$ duty cycle such a possibility is still appreciable (39\%).

\subsection{Thermal equivalency for a group of welders}

Considering following abstract problem, as shown in Table 1.

Table 1. Abstract problem's system specifications for numerical analysis

\begin{tabular}{lc}
\hline Number of welders per group & 20 \\
kVA demand of individual welder & $150 \mathrm{kVA}$ \\
Duty Cycle of Operation & $6 \%$ \\
System Voltage & $400 \mathrm{~V}$ \\
\hline
\end{tabular}

The RMS demand current can be calculated as follows:

$$
\text { emand current }=\frac{k \text { VA Demand }}{\imath_{3} * \text { System Voltage }}
$$

For the mentioned parameters, the RMS demand current is 216A. Had the concept of intermittence not been developed, the straightforward calculation would have resulted in following ampacity requirement for distribution network:

$$
\text { Required Ampacity }=216 * 20=4320 \mathrm{~A}
$$

\subsubsection{Optimistic case: no overlapping}

When only one welder welds at a time there's no overlapping of welding durations. Any new welder starts welding only when no other welder is welding. Figure 3 depicts that the conducting time is "n" times the welding time. In (3) can be reworded as (7) [10]:

$$
I_{t h}=I_{W} \downarrow(n D)
$$

For the considered example, the optimistic value of thermal equivalent current $\left(\mathrm{I}_{\mathrm{th}}\right)$ turns out to be 237A.

\subsubsection{Pessimistic Case: All Machines Weld Simultaneously}

When all of the welders weld at the same time, there's absolute overlapping of welding durations. Figure 4 depicts the overlapping welding peaks. The thermal effect due to " $n$ " welders is " $n$ " times that of a single welder, given by [10],

$$
I_{t h}=n I_{W} \sqrt{ } D
$$


The pessimistic value of thermal equivalent current for the example in discussion calculates to be $1058 \mathrm{~A}$.

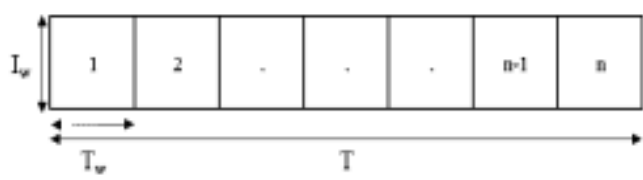

Figure 3. Optimistic case of weld durations overlap i.e. no overlapping
$\mathrm{F}$

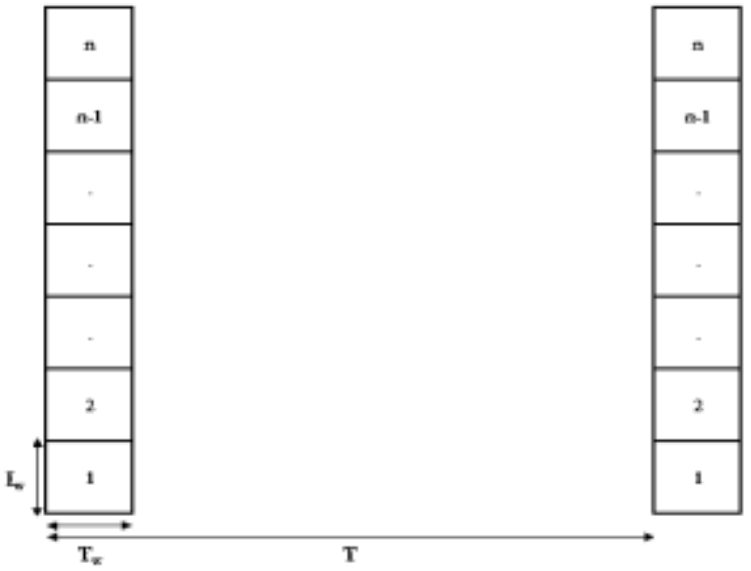

Figure 4. Pessimistic case of weld durations overlap i.e. absolute overlapping

Discussed calculations limit the value of thermal equivalent current for a group of 20 welders, welding at $6 \%$ duty cycle, within the range $237 \mathrm{~A}<\mathrm{I}_{\mathrm{th}}<1058 \mathrm{~A}$.

\subsubsection{Expected value of thermal equivalent current}

For a binomial distribution the expected value is defined as the weighted average of all possible outcomes. The weight assigned to any outcome is equal to its probability of occurrence. In essence, expected value of any distribution or set of random variables is the most expected value of the average or mean of the outcomes if the trial is repeated infinite times. It is used as a means of taking unbiased decisions based on available information [23]. Expected value for a binomial distribution is given by:

$$
\mu=n p
$$

For 20 welders welding at $6 \%$ duty cycle the expected number of welders welding at any instant of time equals 1.2. Although 1.2 number of welders cannot be given a practical thought, however, it can indicate the value of thermal equivalent current one should expect for a feeder feeding 20 welders. The expected value of thermal equivalent current can be equated as:

$$
I_{\mu}=I_{W} \mu
$$

The above relation yields a thermal equivalency of 259A; a more thoughtful and reasonable concord compared to two extremes; 237A \& 1058A.

\subsubsection{Standard deviation as a contingency margin}

Though the expected value of a set of data gives a fair idea about it, the consideration of a contingency factor is appreciable for most practical problems. For this, it's prudent to determine standard deviation of the binomial distribution. The standard deviation tells, how much the members of a data set differ from its expected value. In other words, it measures the dispersion of values of a data set around the mean. For a binomial distribution it is given by [22], [23]:

$$
\sigma=\operatorname{Vnp}(1-p)
$$

For the considered example the standard deviation computes to 1.06. With the standard deviation at hand, the "classical interval" of "one standard deviation plus the expected value" can be considered a fair estimation [24]. It is very probable that any value randomly occurring will lie within the range $\mu-\sigma<\mu<\mu+\sigma$. For this, the expected value and standard deviation are geometrically added yielding a more contingent value of number of simultaneous welding operations. 
$C=\sqrt{ }\left(\mu^{2}+\sigma^{2}\right)$ expressed as:

Similarly, a more contingent value of thermal equivalent current for a group of welders can be

$$
I_{c}=I_{W} C
$$

With $\mathrm{C}=1.6$ for the considered case, the conservative value of thermal equivalent current for a group of 20 welders welding at $6 \%$ duty cycle comes out to be $345 \mathrm{~A}$.

\subsubsection{Ceiling the no. of simultaneous welding operations}

It can be argued that the contingent value of number of simultaneous welding operations determined in the above section is not a whole number. Although it is just a multiplier for the thermal equivalent current, but the motivation towards the determination of an optimal value of thermal equivalent current is also to be able to predict the number of simultaneous welding operations at any instant. Thus, as a resort, the constant multiplier can be mathematically ceiled to give it a practical shape.

In addition, it can be a reasonable upsize, considering that the electrical distribution system is not usually designed at its exhausting capacity. Some breathing space is always allowed as a safety consideration. Based on this, the number of simultaneous welding operations at any instant is given by:

$$
k=\operatorname{Ceil}(C)
$$

Hence the optimal value of thermal equivalent current:

$$
I_{t h}=I_{W} k
$$

For 20 welders welding at $6 \%$ duty cycle, $432 \mathrm{~A}$ is the most optimal value of the thermal equivalent current. This value corresponds to 2 numbers of simultaneous welding operations. Above determined currents are line to line currents for each group (L1-L2, L2-L3 or L3-L1), for feeder sizing however it is essential to evaluate the current to which each line is subjected to. Following relation converts line to line or group currents to line currents.

\subsubsection{Summary of thermal equivalent current calculation for a group of welders}

To conclude, Table 2 presents all the different angles to look at the problem of 20 welders welding at $6 \%$ duty cycle with no interlocking and random initiation times. Table 2 also compares the feeder sizes as per standard ratings for various currents calculated above. It can be observed that the optimal value of thermal equivalent current lies between the determined extremes and is more inclined towards the minimum where major proportion of the simultaneity curve lies. The determined value of number of simultaneous operations " 2 ", covers $88.5 \%$ of the simultaneity curve (Figure 2). In essence, any distribution system designed for 2 nos. simultaneous welding operations, will effectively carry the load for $88.5 \%$ instances.

Table 2. Summary of thermal equivalent current calculation for a group of welders

\begin{tabular}{lccc}
\hline \multicolumn{1}{c}{ Description } & Line to Line Current & Line Current & Feeder size \\
\hline Peak welding current (without thermal equivalency) & $4320 \mathrm{~A}$ & $7482 \mathrm{~A}$ & 2 Nos. 4000A \\
Pessimistic value of thermal equivalent current & $1058 \mathrm{~A}$ & $1832 \mathrm{~A}$ & $2000 \mathrm{~A}$ \\
Optimistic value of thermal equivalent current & $237 \mathrm{~A}$ & $410 \mathrm{~A}$ & $500 \mathrm{~A}$ \\
Expected value of thermal equivalent current & $259 \mathrm{~A}$ & $448 \mathrm{~A}$ & $500 \mathrm{~A}$ \\
Contingent value of thermal equivalent current & $346 \mathrm{~A}$ & $600 \mathrm{~A}$ & $630 \mathrm{~A}$ \\
Optimal value of thermal equivalent current & $432 \mathrm{~A}$ & $748 \mathrm{~A}$ & $800 \mathrm{~A}$ \\
\hline
\end{tabular}

\subsection{Voltage drop analysis}

Determination of voltage drop is specific to the method of power distribution. For a cable, for instance, the method of installation is of prime importance. The same cable laid in a trench will have reduced ampacity in comparison to when it is laid in a cable tray. On the other hand, for bus bar trunking system, the load distribution strategy takes over other factors. Of prime importance, therefore, is to establish the method of power distribution.

For automotive industry the use of high current bus bar trunking systems have far and wide taken over the cable distribution systems with main and sub-distribution networks. The use of tap-off circuit breakers directly installed on the bus bar trunking allows decentralized power distribution. It reduces the space utilization by substituting the floor or wall-mounted switchgear while additionally providing more flexibility in operation. With the use of bus bars, the facility's expandability and refurbishment remain to the creativity of the electrical designer. With smaller cost and more ease of installation and maintenance, the bus bar distribution takes the unprecedented lead in the car manufacturing industry [12], [15], [16]. 


\subsubsection{Voltage drop in a bus bar trunking system}

Voltage drop for a three phase balanced system is given by:

$$
\Delta V=\text { \3.I.L. }\left(R_{L} \cdot \cos \emptyset+X_{L} \cdot \sin \emptyset\right)
$$

It follows directly from (17) that the farther the load from the sending end, the higher the voltage drop supposed to be. In (17), however suffices for only a bulk load at the end of a feeder's length. If there are multiple taps offs along the length of the feeder, which makes the case for bus bar distribution's suitability, there required is a modification.

It can be deduced intuitively, that a bulk load at the farthest end of a distribution network will cause more voltage to drop along the line in comparison to a gradually tapped off load along the length of the distribution network. Figure 5 presents various load distribution cases for evaluation of a compensating factor for the voltage drop

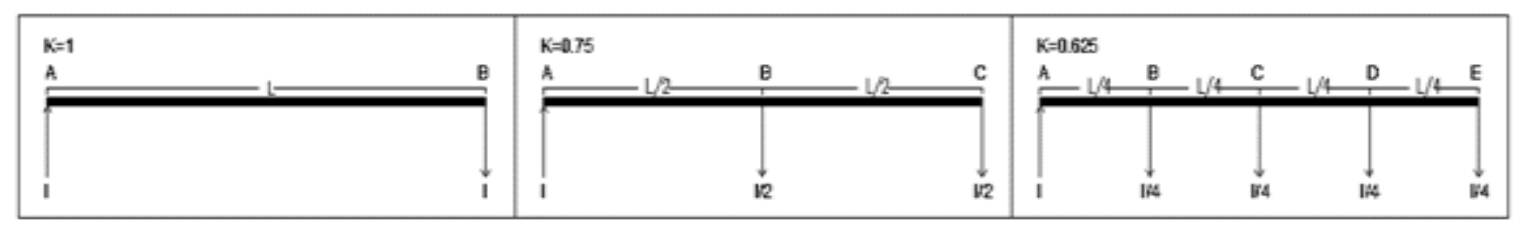

Figure 5. Load distribution cases for bus bar trunking system

Neglecting reactance of the conductor and considering resistive load for the purpose of simplicity, the voltage drop for the cases illustrated in Figure 5 can be expressed as given in Table 3.

Table 3. Voltage drop in various load distribution cases for bus bar trunking system

\begin{tabular}{ll}
\hline Case I: Load at end of the feeder & $\Delta V_{\mathrm{I}}=\sqrt{3}$. I. L. $\mathrm{R}_{\mathrm{L}}$ \\
Case II: Load distributed symmetrically across two equally loaded tap offs & $\Delta \mathrm{V}_{\mathrm{II}}=\sqrt{3} \cdot\left(\mathrm{I} \cdot \frac{\mathrm{L}}{2} \cdot \mathrm{R}_{\mathrm{L}}+\frac{\mathrm{I}}{2} \cdot \frac{\mathrm{L}}{2} \cdot \mathrm{R}_{\mathrm{L}}\right)$ \\
Case III: Load distributed symmetrically across four equally loaded tap offs & $\Delta \mathrm{V}_{\mathrm{III}}=\sqrt{3} \cdot\left(\mathrm{I} \cdot \frac{\mathrm{L}}{4} \cdot \mathrm{R}_{\mathrm{L}}+\frac{3 \mathrm{I}}{4} \cdot \frac{\mathrm{L}}{4} \cdot \mathrm{R}_{\mathrm{L}}+\frac{\mathrm{I}}{2} \cdot \frac{\mathrm{L}}{4} \cdot \mathrm{R}_{\mathrm{L}}+\frac{\mathrm{I}}{4} \cdot \frac{\mathrm{L}}{4} \cdot \mathrm{R}_{\mathrm{L}}\right)$ \\
\hline
\end{tabular}

Generalizing expressions for above cases, for " $n$ " number of tap offs:

$$
\begin{aligned}
& \Delta V_{n}=\text { 须. }\left(I \cdot \frac{L}{n} \cdot R_{L}+\frac{(n-1) I}{n} \cdot \frac{L}{n} \cdot R_{L}+\frac{(n-2) I}{n} \cdot \frac{L}{n} \cdot R_{L} \ldots+\frac{I}{n} \cdot \frac{L}{n} \cdot R_{L}\right) \\
& \Delta V_{n}=\Delta V\left(\frac{1}{n}+\frac{n-1}{n}+\frac{n-2}{n}+\frac{n-n+1}{n}\right)
\end{aligned}
$$

Summing $\left(\frac{1}{n}+\frac{n-1}{n}+\frac{n-2}{n}+\frac{n-n+1}{n}\right)$ as an arithmetic series:

$$
\Delta V_{n}=\frac{n+1}{2 n} \cdot \Delta V
$$

Represented by " $\mathrm{K}$ ", $\frac{n+1}{2 n}$ is designated as load distribution factor. Incorporating load distribution factor, in (17) can be rewritten as (21) [16]:

$$
\Delta V=K \cdot \text { 须. I.L. }\left(R_{L} \cdot \cos \emptyset+X_{L} \cdot \sin \emptyset\right)
$$

\subsubsection{Voltage drop calculation for the case of 20 welders}

Revisiting the case of 20 welders connected to a group, welding at $6 \%$ duty cycle. It has been established as part of thermal current calculation that a feeder with an ampacity of $800 \mathrm{~A}$ shall suffice for the said distribution. Further, in (14) establishes 2 number of simultaneous operations. It should be noted that for 2 simultaneous operations per group, there shall be 4 simultaneous welding peaks for each phase. Figure 6 details the same. 


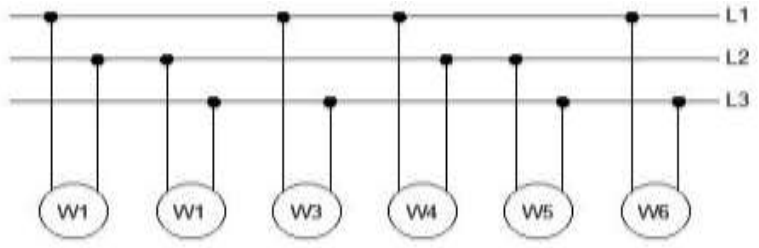

Figure 6. Depiction of two phase welding load on three phase network

Assuming that the loads simultaneously operating shall be symmetrically distributed along the length of the feeder, the load distribution factor can be calculated as 0.625 . Factors $R_{L}$ and $X_{L}$ can be obtained for the selected bus bar from the manufacturer's datasheet. Following is a brief summary of some typical bus bar sizes and the respective resistance and reactance values, for two bus bar manufacturers, as shown in Table 4.

Table 4. Impedance reference values, for two bus bar manufacturers [25], [26]

\begin{tabular}{|c|c|c|c|c|c|c|}
\hline \multirow{3}{*}{ Feeder Rating } & & \multicolumn{5}{|c|}{ Impedance Reference Values $(\mathrm{m} \Omega / \mathrm{m})$} \\
\hline & & \multicolumn{3}{|c|}{ Siemens } & \multirow{2}{*}{\multicolumn{2}{|c|}{$\begin{array}{c}\text { Schneider } \\
\boldsymbol{X}_{\boldsymbol{L}}\end{array}$}} \\
\hline & & $R_{L}$ & $X_{L}$ & & & \\
\hline $250 \mathrm{~A}$ & & 0.375 & 0.128 & & 0.39 & 0.16 \\
\hline $400 \mathrm{~A}$ & $\ll$ & 0.215 & 0.122 & 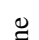 & 0.21 & 0.14 \\
\hline $630 \mathrm{~A}$ & กี & 0.134 & 0.065 & $\exists$ & 0.13 & 0.07 \\
\hline $800 \mathrm{~A}$ & $\overrightarrow{0}$ & 0.098 & 0.057 & $I$ & 0.09 & 0.06 \\
\hline $1000 \mathrm{~A}$ & & 0.066 & 0.057 & & 0.06 & 0.06 \\
\hline
\end{tabular}

Values for both the manufacturers are largely identical, and as a simpler resolve, worse of the two may be considered for calculation. Power factor for resistance spot welders is usually between $30 \%$ and 50\% [10]. Considering $50 \%$ power factor and an arbitrary feeder length of $50 \mathrm{~m}$ the voltage drop turns out to be:

$$
\Delta V=0.625 .13 .4 .375 .50 \cdot(0.098 \cdot 0.5+0.057 \cdot 0.866)=7.98=2 \%
$$

It should be noted that the current used for calculation is the number of simultaneous operations times' peak welding current instead of the calculated thermal equivalent current of 748A. It must be acknowledged that the thermal equivalent current is not a physical entity and shall not be measurable, although it can be calculated through energy analysis. The voltage dropped along the feeder impedance will be due to the current flowing at an instant which in this case is the peak current for 4 welders. At $2 \%$ comes out to be the voltage drop for the bus bar feeding the welding load, however there can be an elaborate system at the back end of the welding bus bar. The total voltage drop that needs to be contained within the welding limits, need to be evaluated by detailed system analysis and added to this calculated value.

\subsection{Evaluation of quality of weld}

Calculation of voltage drop and the same being within allowable limit for say $10 \%$, does not suffice the welding quality criteria. The voltage drop limit is to be seen in conjunction with the allowable proportion of bad welds. Let the example of 20 welders allow one in 10,000 bad welds i.e. $\mathrm{P}_{\mathrm{b}}=0.01 \%$. Which means that once in 10,000 welding operations the voltage is allowed to drop below 10\%. As explained earlier this limit is subjective of the welding application and must be decided by operations team at site. The cost of rectification and the process cessation in due course need to be taken in account. Since voltage drop calculation method is already established in previous section, if worked out in reverse sequence, the number of welders for which the voltage drops below $10 \%$ can also be determined. Consequently the probability of that many welders welding at a time can be determined using (4). If the calculated probability turns out to be smaller than the allowable proportion of bad welds, the system can be seen as optimally designed.

In order to work out reverse solution, it is significant to identify the factors in voltage drop calculation that shall change as the number of simultaneous operations changes. In (21) it can be observed that factors except K \& I are independent of number of welders and form the designed system's property. If $\mathrm{W}^{\prime}$ ' be the number of welders for which the voltage drop valuates the voltage drop limit, $K^{\prime}$ and $I^{\prime}$ represent the load distribution factor and peak welding current corresponding $W$ ' welders respectively, following relation can be written:

$$
\Delta V^{\prime}=\frac{\Delta V}{K \cdot I} \cdot K^{\prime} \cdot I^{\prime}
$$


Re-writing at (23) in terms of number of welders:

$$
W^{\prime}=\frac{\Delta V \cdot \cdot K \cdot W}{\Delta V \cdot K^{\prime}}
$$

Since the number of welders $\mathrm{W}^{\prime}$ is not known, it is not possible to calculate the load distribution factor, however it can be thoughtfully generalized. In order to derive any valuable conclusion regarding the value of $\mathrm{K}^{\prime}$, it is prudent to have some values at hand. Figure 7 shows the load distribution factor for up to 100 equally loaded and symmetrically distributed tap offs.

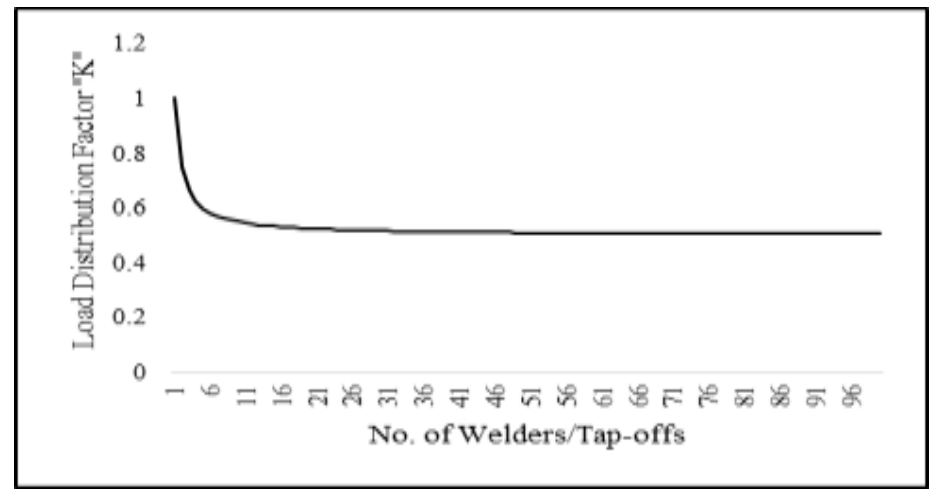

Figure 7. Load distribution factor "K" vs no. of welders/tap-offs

From Figure 7, it's indubitable that the load distribution factor approaches a value of 0.5 . Further Table 5 establish that a value less than 0.5 is inevitable in a practical scenario.

Table 5. Load distribution factor for very high number of tap-offs

\begin{tabular}{cc}
\hline Number of tap offs & Load distribution factor "K" \\
\hline 500 & 0.501 \\
1000 & 0.5005 \\
\hline
\end{tabular}

It should also be understandable that higher the selected value of K', smaller will be the number of simultaneous welders. A value of 0.55 stands an apt choice after multiple iterative calculations. For 1 to 8 number of tap-offs, however a load distribution factor of 0.55 will give a value higher than actual, which is why an iterative voltage drop calculation is necessary if the calculated number of welders lie in the range 1-8.

Having determined $\mathrm{K}$ ', we evaluate $\Delta \mathrm{V}^{\prime}$. As earlier discussed, let $10 \%$ be the limit of voltage drop corresponding to the allowable proportion of bad welds. Let the voltage drop in upstream network be $2 \%$. Therefore $8 \%$ of $400 \mathrm{~V}$ (reference voltage) shall be used in calculation. The calculation follows as (25):

$$
\begin{aligned}
& W^{\prime}=\frac{32.0 .625 .4}{7.98 \cdot 0.55} \\
& W^{\prime}=18.22 \approx 18 \text { welders }
\end{aligned}
$$

Since 18 does not lie between 1 and 8, there's no need to re-calculate voltage drop using 18 no. of welders. Next to the calculation of number of welders for which voltage drops below the limit of $10 \%$, is the evaluation of the probability of this many welders welding at a time. Employing Bernoulli's equation to determine the simultaneous welding probability of 18 out of 40 welders connected to a line (L1/L2/L3).

$$
\begin{aligned}
& P_{18}=\left(\begin{array}{l}
40 \\
18
\end{array}\right)(0.06)^{18}(1-0.06)^{40-18} \\
& P_{18}=2.95 \times 10^{-10}
\end{aligned}
$$

Since $\mathrm{P} 18<\mathrm{Pb}$, the criteria of voltage drop and weld quality are duly met. It can be concluded that the $800 \mathrm{~A}$ rated distribution bus bar is an optimal selection for the discussed system. 


\section{RESULTS AND DISCUSSION}

An outcome of this research and thorough numerical-based exemplification of various design requirements is an effective and user-centric Microsoft excel based design tool. This tool allows a designer to input project-specific information and yields all the parameters of designers' interest, in essence, the number of welders most probable to be welding simultaneously, the thermal equivalent line to line current, thermal equivalent line current, voltage drop, and the probability of the voltage dipping below the allowable limit.

Figure 8 is an illustrative example of the design tool's framework and functionalities. Presented is the face of the tool that accepts the user's inputs and summaries the calculation results. Besides, detailed step-wise calculations are also provided in subsequent tabs to help a designer understand the physical implications of each step of design.

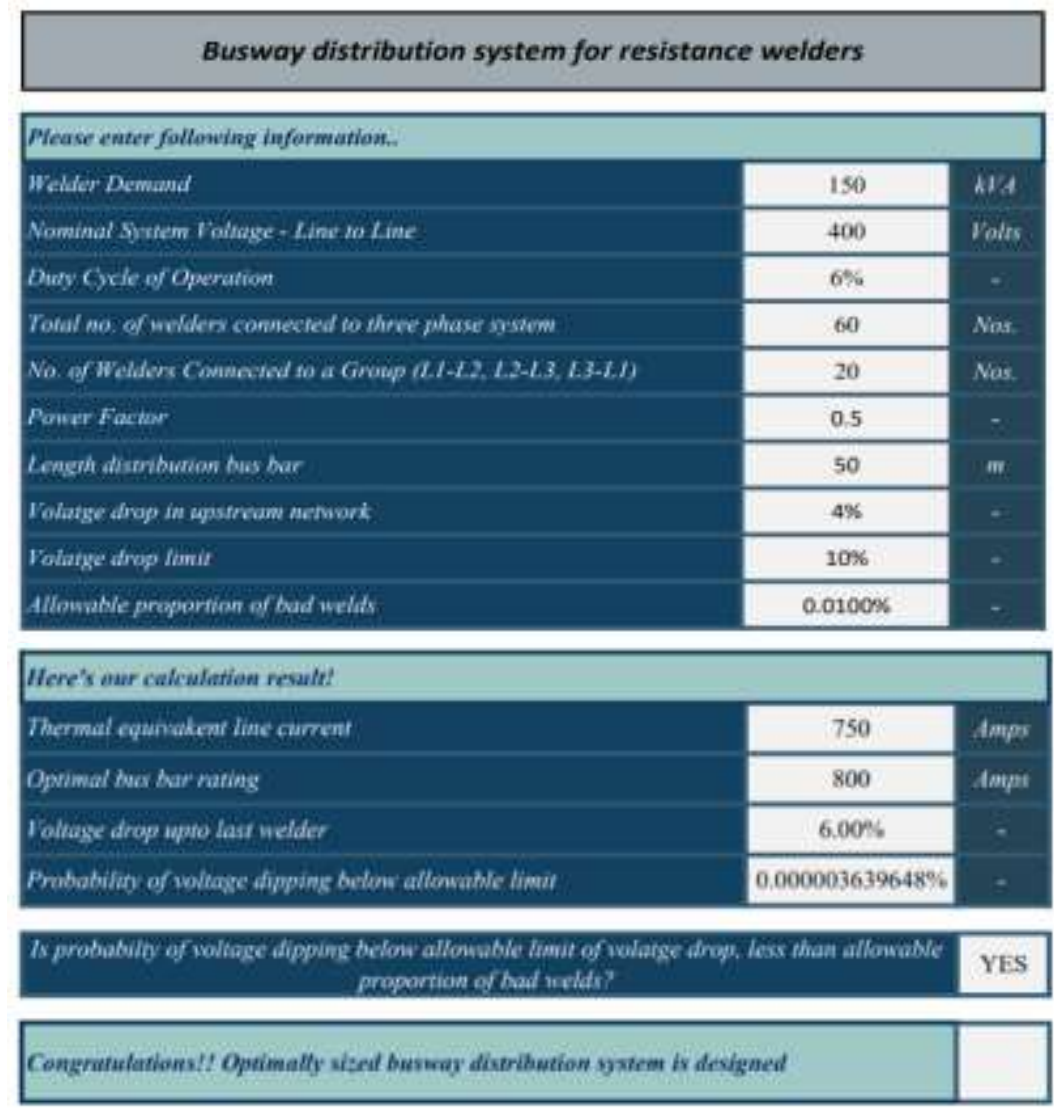

Figure 8. Illustrative example of design tool's framework

\section{CONCLUSION}

Designing a weld shop is a challenging sport. The supply and distribution system schemes cannot be in line with conventional designs. A system designed without consideration of the peculiarities of the welding operation and weld shop quality control requirements, shall not be an optimal design. Such a design shall not necessarily cease to function, but it shall cost hefts in terms of initial investment, operation, maintenance, and occupancy of undeserved pricey space. The course of the discussion of this paper, well established the need for process-dependent electrical distribution system designing for automotive weld shop. An 800A busway proved to be sufficient for a ten times higher connected welding load. Additionally, a handy design tool has been developed to supplement the fast progressing industry's needs. Moreover, for a distinctive problem like this, effort may be invested in developing a means to look into the system with a wider perspective. Such a means could be best supplemented in form of a software or an interactive simulation. 


\section{ACKNOWLEDGEMENTS}

Authors would like to acknowledge Ayesha Arif for her insightful suggestions, technical support and guidance and M/s. Fahim, Nanji \& deSouza (Pvt.) Limited for sharing their invaluable collection of technical literature and practical experience.

\section{REFERENCES}

[1] K. Zhou and P. Yao, "Overview of recent advances of process analysis and quality control in resistance spot welding," Mechanical Systems and Signal Processing, vol. 124, pp. 170-198, 2019, doi: 10.1016/j.ymssp.2019.01.041

[2] Canalis busbar trunking Technical Guide Automotive industry, Schneider., 2014. [Online]. Available: https://download.schneider-electric.com/files?p_Doc_Ref=KD0C98CTAAUEN\&p

[3] Andersson, O, "Process planning of resistance spot welding," Doctoral dissertation, Production Engineering, KTH Royal Institute of Technology, 2013.

[4] S. Naik, M. A. Devi, and C. P. S. Prakash, "A Review on Optimization of Resistance Spot Welding of Aluminum Components Used in Automotive Industry," International Journal of Innovative Research in Advanced Engineering (IJIRAE), vol. 4, no. 4, 2017.

[5] D. H. Moon, H. I. Cho, H. S. Kim, H. Sunwoo, and J. Y. Jung, "A case study of the body shop design in an automotive factory using 3D simulation," International Journal of Production Research, vol. 44, pp. 4121-4135, 2006, doi: 10.1080/00207540600806430.

[6] S. Aktas, U. Ozsarac, and S. Aslanlar, "Effect of Spot Welding Parameters on Tensile Properties of DP 600 Steel Sheet Joints," Materials and Manufacturing Processes, vol. 27, no. 7, 2012, doi: 10.1080/10426914.2011.647940.

[7] M. Hamedi and M. Atashparva, "A review of electrical contact resistance modeling in resistance spot welding," Welding in the world, vol. 61, no. 2, 2017, doi: 10.1007/s40194-016-0419-4.

[8] H. Zhang and J. Senkara, "Resistance welding: fundamentals and applications," Second ed. CRC Press Taylor \& Francis Group, 2011.

[9] W. K. Boice and J. T. Jamison, "How to Distribute Power to Resistance Welders," 1956.

[10] H. Kiank and W. Fruth, "Planning Guide for power distribution plants. Germany: Publicis Publishing," Erlangen, 2011.

[11] J. Farrow, "Sizing the Primary Power System for Resistance Welders," 2004.

[12] H. Kiank, "Process-Dependent Planning of Power Supply Systems for an Automobile Plant, Siemens," 2003.

[13] Fisher, L. E., and Dailey, R. W., "A new welder busway distribution system," Transactions of the American Institute of Electrical Engineers, Part II: Applications and Industry, vol. 79, no. 3, pp. 203-215, 1960, doi: 10.1109/TAI.1960.6371667.

[14] B. Rogers, M. Stephens, P.E., and M. McGranaghan, "Power Quality Issues and Solutions in the Automotive Industry," in 2004 International Conference on Power System Technology, 2004. PowerCon 2004., 2004, doi: 10.1109/ICPST.2004.1459999.

[15] Busbar trunking Canalis For automotive industry, Schneider Electric Industries SAS, 2014. [Online]. Available: https://www.se.com/id/en/download/document/guide_solution_automobile/

[16] Totally Integrated Power-Planning of Electric Power Distribution Products and Systems Busbar Trunking Systems, Simens, 2019. [Online]. Available: https://assets.new.siemens.com/siemens/assets/api/uuid:2c3de840-6ece-4de5ba4e-831e8e837e3a/planning-of-electric-power-distribution-busbar-trunking-systems-.pdf

[17] T. G. Vaidya, "Application of active load balancer in spot welding machine loads," in 2014 IEEE International Conference on Power Electronics, Drives and Energy Systems (PEDES), 2014, doi: 10.1109/PEDES.2014.7042094.

[18] J. Saleem, "Power Electronics for Resistance Spot Welding Equipment," Doctoral dissertation, Department of Information Technology and Media, Mid Sweden University, 2012.

[19] A. C. Moreira, L. C. P. d. Silva, and Helmo K. M. Paredes, "Power Quality Study and Analysis of Different Arc Welding Machines," Journal of Control, Automation and Electrical Systems, vol. 29, no. 2, pp. 163-176, 2018.

[20] "Power supply for resistance-welding machines," in Electrical Engineering, vol. 59, no. 5, pp. 306-320, May 1940, doi: 10.1109/EE.1940.6434924.

[21] J. F. Deffenbaugh, Electrical Power as Related to Resistance Welding Machines, 2004. [Online]. Available: http://www.weldtechcorp.com/documentation/smwc2004/deffenba.pdf

[22] A. Barone, Binomial Distribution, Investopedia, 2020. [Online]. Available: https://www.investopedia.com/terms/b/binomialdistribution.asp

[23] Discrete Random Variables, Mean or Expected Value and Standard Deviation, Lumen. [Online]. Available: https://courses.lumenlearning.com/introstats1/chapter/mean-or-expected-value-and-standard-deviation/

[24] Eur-Lex, State aid scheme implemented by Italy to remunerate Poste Italiane for distributing postal savings certificates, Official Journal of the European Union, 2008. [Online]. Available: https://www.legislation.gov.uk/eudn/2009/554/adopted

[25] Power and data via busbar SIVACON 8PS Busbar Trunking System, Simens, 2016. [Online]. Available: https://new.siemens.com/global/en/products/energy/low-voltage/systems/8ps-busbar-trunking-systems.html

[26] Schneider Electric Busway, I-Line II, Schneider Busway (Guangzhou), 2017. [Online]. Available: https://download.schneider-electric.com/files?p_enDocType=Catalog\&p_File_Name=01_Schneider+ILine+II+catalogue+2017.pdf\&p_Doc_Ref=SBGI17V2 